\title{
Significant Life Events of Aging
}

\author{
MARIA AMY FIEL T. RACINES \\ http://orcid.org/ 0000-0002-0000-7689 \\ maftracines@universityofbohol.edu.ph
}

\begin{abstract}
Significant life events are bound to happen at any phase in life. The aging process alone reveals recognizable life events that are inevitable, which the different biologic and social theories tried to come up with explanations. Amid the changes, which one seemed to dominate? Understanding this phenomenon is essential not only for the elderlies to prepare but as well as for the significant others and people in the health care arena to understand. This study aimed to assess the significant life events that affected change among elderlies. This research is qualitative that employed interpretative phenomenology, utilizing Hermeneutic approach in the data gathering process. The informants were the seven elderlies from the first district of Bohol, age 60 years old and above chosen through purposive sampling. An in-depth interview was conducted to gather the data which focused on the life events experienced by the informants and how it affected change. The data were transcribed, interpreted, and analyzed to come up with the common meaning of the lived experience. The findings of the study pointed out to four themes; a.) Advancing age, declining health, and vanishing resources, b.) Retirement: the inevitable moment and uncertainty of what lies ahead, c.) the loss of a loved one and the accompanying pain and d.) The moment of change and living with life's changes. These four themes explain the conclusion that the aging process brings about significant events such as the decline in health, uncertainty in Retirement, and the possible loss of loved ones. These events affected change to the individuals' lives.
\end{abstract}


Keywords: Significant events, affect change, qualitative method, phenomenology, Bohol, Philippines, Asia

\section{INTRODUCTION}

Living life would mean navigating through varied life events that bring about changes and challenges which one needs to overcome in an attempt to maintain wellbeing. The Health and Place Initiative (2014) illustrates the different changes that aging process brings prominently on the physical and social aspect. Change in this sense is predictable, as it is expected to happen in a lifetime, such as the time to retire after years of working.

In the perspective of the elderlies, which of these changes would they consider significant and worth preparing? The Response to Life Change theory recognizes the inevitability of life events that may take place at a certain point in life. However, although foreseeable, often, the timing of its onset catches one in a disadvantageous position like in a loss of a loved one or the emergence of a disease condition, creating an impact to one's life. It is for this reason that one is expected to change as he recognizes the internal disequilibrium that the event has affected. It is in this aspect that the individual may react to the said event by initiating change to maintain internal balance. However, in the process of responding to change, a varied adjustment must be undertaken to regain homeostasis. Thus what is perceived to affect change based on what he considers as a significant event in life need to be understood to support him as he tries to regain balance.

The aging process is one life event that is considered to be lifechanging. The tenet of this study includes the assessment of the significant life events in aging, and how it affected change to the person, especially among elderlies who are in the prime of their lives as they adjust themselves to the new life situation. It is based on the perception that they are the most vulnerable individuals. Alley, Putney, Rice, \& Bengtson (2010) define the conversion of the aging person from a healthy to a physically challenged one caused by the decline of the biological functions, and the inability to adjust to the metabolic change in which the effect is often irreversible. Thus, the process of aging per se is enough to bring a lot of changes to the person affecting his physiologic, psycho-emotional, and socio-experiential aspects of life. 
Changes confronting the middle-aged adults include carrier change affecting financial stability, maintaining social contact and addressing health needs, and the care of the sick loved ones. While lesbians, gays, bisexuals, and transgender expressed fear of inability to care for self when being disabled, and being discriminated (Lavretsky, 2014). These are some of the life events that are considered to be life-changing and can make an individual vulnerable.

This study was done to recognize the significant life events experienced by the elderlies and how it affected them, as they express suppressed feelings and recall things that are both painful and not. Their ability to sustain balance from the said experiences can be a good avenue for the elderlies to realize their inner strength and capacity to withstand challenging situations, and recognize present and more available resources that can assist them, as they prepare for more challenging life-changing events. Since the idea of the significant events and changes comes from them, it would be easier for them to relate to the experience.

At the same time, this study is expected to pave the way for the community to realize how they can provide support to the elderlies and even to their families. The result of the study can also be an eyeopener for various agencies such as the Department of Social Welfare and Development (DSWD) or non-government organizations (NGO) that caters to the needs of the elderlies who have the prerogative to come up with programs which are not yet perceived as vital for the elderlies, as hearing directly from the ones concerned may somehow influence the decisions of the concerned agencies to come up with sound programs. More so, this study can also be an essential tool for nurses and other health providers in the health care arena to be more aware of the things, that the elderlies are going through and their possible silent struggles. The ability to identify the elderlies concern will provide means to come up with holistic care, geared towards the attainment of a quality of life among individuals who are in the prime of their lives.

This study aimed to assess the significant life events that affected change among elderlies. Specifically, it sought to find answers to the following objectives: To describe the significant events experienced by the informants and to determine the impact of the said events in their lives. 


\section{METHODOLOGY}

This study is qualitative research that employed interpretative phenomenology, utilizing Hermeneutic approach. The goal of using this method is to analyze and interpret a phenomenon as experienced by the informants (Laverty, 2003). According to Laverty (2003), this research strategy will allow understanding of the phenomenon such as how change can create the complexity of responses, and how the informants responded to the situation without subjecting the answers to statistical treatment, but by giving meaning to their lived experience. This strategy enabled the researcher to dig deeper and find salient suppressed information of the phenomenon being studied based on the informant's narration of their own experience, and its impact to them, without biases as the information solely came from the informants.

The gathering of the data was done through an in-depth interview with the informants. It was then transcribed verbatim to come up with the written text, and the transcript was read several times to ensure accuracy and allowed the researcher to be soaked with the data and to note distinctive phrases and emotional responses that can be valuable information for the study. The emergent themes were identified based on commonalities of the description of the experience of the informants, and it became the meaning of the lived experience (Munhall, 2007). The themes created from this study reflected the significant events and how they affected change to the individual.

The conduct of the study was done in the dwellings of the informants within the first district of the province of Bohol, where the livelihood of the people varies from fishing to farming and employment in various agencies. To add to this possible source of rich experience is the exposure of the people to the 7.5 magnitude earthquake in October 2013 which resulted to the devastation of structures including houses, loss of lives, poor unregained health and even loss of livelihood. The number of informants was based on data saturation, and they were chosen through purposive sampling. This strategy allowed the researcher to handpick those that best qualified to the study.

The recruitment of the informants was based on this given inclusion criteria: elderlies must be 60 years old and above, male or female, either currently working or not, and who either lived with their families or living alone, and of sound minds. The recruitment excluded elderlies who were bedridden and hospitalized due to recurring chronic 
illness as well as those who find it difficult to remember and comprehend their thoughts. The inclusion criteria allowed the researcher to maximize extraction of firsthand information of lived experiences of the elderlies in various settings.

The conduct of the study was done after the approval of the Cebu Normal Ethics Review Committee. The researcher also sought the permission of the office of the governor before the recruitment process. The data collection was explained to the informants, and the information sheet was handed down and reviewed to facilitate understanding of the process of the study. They were also allowed to ask questions and clarifications in their participation in this research.

The informants were requested to provide honest answers to the queries asked in the data gathering process. They were made to realize the need for the truthfulness of responses as one of the concern of this study, and the inability to provide this may inhibit them from participating in the said study. To assure the accuracy of the data gathered, the researcher also asked permission from the informants to use a voice recorder to record the conversation, which will facilitate the organization of the information collected.

Since the interview required the informants to remember and narrate both painful and happy events in their lives which can be emotionally and psychologically taxing, the informants were advised to withdraw or temporarily suspend the interview until they can regain emotional control. It is also for the above reasons that the informants were encouraged to express willingness to request for the presence of her significant others if they wish. Thus, the informants took full responsibility of their own emotions and feelings and to inform the researcher or to call the doctor in the event of his or her need for medical intervention which may arise in the middle of the interview.

After the informants decided to take part in the study, the schedule of the said interview was agreed based on their preference. The interview which was done in vernacular, and focused on two-point questions which led to the discovery of the life-changing events experienced by the informants, and how it affected change. The guide questions consisted of the following; what are the recent events in your life that you consider as significant? How did the experience affect you?

Transcription of the data followed, and the data gathering ended after saturation was attained. The transcript was read several times to ensure the accuracy of the information gathered. This process also allowed the researcher to be soaked with the data and to note distinctive 
phrases and emotional responses that can be valuable information for the study. Further, the different life events came out to be very significant based on the description of the respondents.

\section{RESULTS AND DISCUSSION}

Based on the data gathered from the seven informants, life events pointed out to both desirable and undesirable situations. However, the key findings on the significant life events focused more on the unwanted experiences which became the meaning of the lived experience, and basis of the four major themes of this study: the advancing age, declining health, vanishing resources, retirement: the inevitable moment and uncertainty of what lies ahead, the loss of a loved one and the accompanying pain, and the moment of change and living with life's changes.

\section{Theme 1: The Advancing age, declining health, vanishing resources}

This theme reflects the significant life events as one reaches the prime of his life. The experience echoed the reality that as age continues to increase, there follows a decline in health. The experience led to financial strain, losing quality time battling for different concerns, and even the loss of one's life affecting the individual and the family as a whole.

Mrs. C.H, a 62-year-old housewife and a mother of two children, claimed to have felt a lump on her right breast. This observation followed the diagnosis of cancer in 2013, which caused her to undergo a mastectomy on that same year. However, she claimed that she did not undergo chemotherapy after the operation despite the doctor's recommendation due to financial reasons. According to her; they were talking of the amount ranging between $75,000.00$ to $90,000.00$ pesos per session. She further asked, "where will I get the money for that? I don't want my family to end up begging just for me to live. I don't want them to end up with nothing because of my condition." She further claimed that just one month after her surgery, the occurrence of earthquake ruined their house. "That incident led me to arrive at my final decision. I will not undergo Chemotherapy." Last year, barely four years after her surgery, she had a persistent cough. Knowing her history, she said, "the doctor convinced me to undergo CT scan of my lungs, and he found out that cancer has reached my lungs." Recently, she was convinced to at least take the oral chemotherapy which she claimed: "It is still very costly, as 11 tablets would cost 28,000 pesos." 
Mrs. L.D is a 62-year-old teacher and a single parent of 2 children. She claimed that her retirement at her age is still untimely. "I don't want to retire yet because my son is still in grade nine and I am planning to retire after he graduates senior high school." However, her present health condition would require her to do so. According to her, "I cannot stand the pain anymore." She sought medical help and was diagnosed and advised to undergo surgery as soon as possible. She had cancer of the uterus which has spread to her intestine since May 2017. She further claimed that "a big fraction of my retirement money went to hospitalization and medication. I have no other option; I have to because I care for my children". The surgery was indeed successful, but she wasn't able to start with the anticancer medication on time after surgery which caused the lumps to recur in her intestine. "In as much as I wanted to start taking the medications, but, I needed to wait for the money from my retirement, as one course of my medication for one month would cost 150,000.00."

Mrs. L.T is a 63-year-old housewife. She claimed to have explicit and disturbing manifestations of postmenopausal which she felt when she was 53. It caused her to seek medical help as well as hospital admission. Her present concern above all was the recurrence of the symptoms, which again resulted in hospital admission. She further claimed that "It is very hard to cope as the manifestations would include an intense headache, palpitations, epigastric pain, and fear with no particular reason." Further, she had unexplained sadness, inability to sleep and forgetfulness, she said, "and all these suddenly recurred now, ten years after I had my menopause." She further complained of her extreme forgetfulness as one of the significant changes that she has manifested lately. A complete laboratory test was done to her, which included a transvaginal ultrasound to rule out other conditions. There was nothing unusual except for her elevated BP which has been addressed already since she was 50, and was just advised to continue with her anti-hypertensive maintenance. The doctor reminded her of the symptoms as part of her postmenopausal. But despite the explanation given by the doctor, she stated that "even if it is considered a normal process, but I still feel like I am slowly losing my senses."

Mrs. N.A is a 60-year-old married woman who expressed concerns about her on and off the knee pain. "There are times when my knee gets inflamed" as claimed by her. Despite her condition, she stated, "I can still manage to do the work expected of me as an office utility worker." She was dismissed from her job even if she claimed as capable based on the 
observation of the unit manager. She narrated, "I was terminated from work because according to my manager, I am already of age, and I have arthritis, and he was afraid that I might stumble down." It caused her to burst in anger because she strongly thought that she was still capable of the job. The researcher asked her. "Does your knee pain bother you?" because the researcher had also noticed the inflammation of her knees and a change in her gait. She answered quickly, "Yes, at times, but this is just normal." She also added, "this is just joint pain, I will just apply liniment and it's gone," a reason that justifies her claim of her capability to function as an office utility to keep her job.

Problems with regards to health came out as one of the significant events affecting the informants. It ranges from simple to complicated ones from what is considered normal to life-limiting disorders. One of the conditions cited was the onset of Osteoarthritis. Such was regarded as usual as one informant said, "This is just joint pain, I will just apply liniment, and it is gone." It can never be denied that the elderlies view joint pain and inflammation of the knees as a package deal for aging. They find the condition as a usual process which medicine can do little (Grime, Richardson \& Ong, 2010). How they view osteoarthritis is the reason why they would resort to self-medication and endure the pain (SingHealth, 2016).

Studies conducted revealed that joint pain is never considered a hindrance to wellness by the elderlies. The component of health for them is the ability to perform the activities of daily living (Grime, 2010). This claim was evident when the informants stated that "I can still manage to do the work expected of me as an office utility worker" and claimed that her joint pain is just average. Her dismissal from her job is what made her osteoarthritis as a significant event. The informant may not have loss her money for medical care, but her physical condition still led to the loss of her job which may require a readjustment in every aspect especially regarding finances as evident on her reaction of anger from losing her job.

On the other hand, the process of postmenopausal was claimed as a very difficult, disturbing and an impactful condition by another as she said, "Even if it is considered normal, but it seems like I am losing my senses." This statement comes from a disappointed 63-year-old lady who claimed of the alarming manifestations of postmenopausal. Some elderlies are lucky enough to be spared from these.

Menopause can post challenges to the physical, social, and psychological wellbeing as the individual. Mrs. L.A stated, "It is tough as 
the manifestations would include an intense headache, palpitations, epigastric pain, and fear with no particular reason, unexplained sadness, inability to sleep and forgetfulness. All these suddenly recurred now, 10 years after my I had my menopause." The woman can have different symptoms because the manifestations are individualized from almost nothing to very overwhelming physical and psychological symptoms. According to Nordqvst (2017), The common complains of the women include hot flashes, night sweats, disturbed sleep, extreme loneliness, irritability, poor concentration, and anxiety. These are just some of the symptoms mentioned which may recur, such as in the case of the informant.

The cause for the extended period of symptoms that comes and go can be attributed to the fluctuation of hormones during this time (Australian Menopause Center, 2015). The informant mentioned of seeking medical help. However, she was informed that her manifestations are for women on menopausal. To counteract the symptoms, she stated ways to divert her attention which even included avoidance from staying at home or being alone which robs her of her precious time to spend according to how she wishes.

The malignancy or diagnosis of cancer of the two mothers caught them amid the reality of it as a life-threatening condition. Their cancer is a condition that can end their lives at any point. According to Mrs. $\mathrm{CH}$, "I cried hard when I discovered the lump on my breast." Wallis (2014) states that it is not too surprising to hear concerns similar to the complaints of $\mathrm{C} . \mathrm{H}$ as while cancer strikes younger people, it continues to be the leading cause of morbidity for the graying individuals. The diagnosis of cancer does not limit to the individual, but the entire family is seemed to be counted in the diagnosis as Mrs. C.H claimed; "We were sitting together, we did not say anything, but we just cried. It is like a confirmation of what we were afraid of," she added, "I pity my children, and they do not have any idea about hospitalization and walking around Cebu City to buy my medications. But we are left with no choice, they needed to serve as my hospital watcher" are statements which manifest the involvement of the whole family. Due to the family's involvement, in the diagnosis of cancer, the family may also end up manifesting signs of depression and anxiety (Edwards, 2004). Both mothers underwent surgery as recommended immediately. However, it came out that in the continuous process of the treatment regimen money emerged to be a hindrance on their effort towards recovery. The need for 
financial resources affected how one responds to the situation putting into consideration the life of the whole family. Statements such as; "It's too expensive, where will I get the money? It is too costly. I don't want my family to end up begging just for me to live, and I don't want my family to end up with nothing just because of me." These are statements of dismay of the condition. One informant came up with an expression of hope as she said, "I don't care if a big fraction of my retirement money went to hospitalization and medication. I have no other option because I care for my children." She wanted to start with the anticancer therapy after her operation, but she has no other way to start it. She said, "In as much as I wanted to start taking the medications, but, I needed to wait for the money from my retirement. As one course of my medication for one month would cost P150,000.00." It caused the lumps in her intestine to recur. Financial resources seemed to be the burden facing the families of cancer patients.

The scenario on the difficulty of sustaining the treatment regimen for cancer is not only true in the Philippines, as the United Kingdom is also faced with challenges of financial constraints caused by increasing health care budget on cancer (Kenedy, 2016). This scenario seems to rob the person with the right to live because of the corresponding cost that goes with it, thus leaving them with no choice but to allow fate to take its course in the process. This situation reflects that life is indeed priceless that people often find a way to keep it at its best and enjoy it. However, when faced with difficult situations, the individual may end up giving it up to his personal preferences instead of what is best for everyone, or because they run out of options.

The decline in the health conditions is already expected as the person advances in age. According to the Immunological theory, the waning up of the function of the immune system is expected over time which leads to the decline in health with age, onset of diseases such as cancer and even death, (Jin, 2010). And the Wear and tear theory describes this phenomenon as a deteriorative process. Newman's theory explains the task that must be accomplished in the process of aging which includes adjusting to changes in health, and reaching a conclusion on the concept of death as 2 of the four tasks to be accomplished (Williams, 2016).

The findings reveal that the significant events in life as age advances include, the decline in health that can trigger the loss of other resources. Thus, the significant events in the lives of the informants point out to one phenomenon, that advancing age ushers one to the decline in health and vanishing resources, and the above theory justifies this phenomenon. 


\section{Theme 2. Retirement: the inevitable moment and uncertainty of what lies ahead}

Another event considered by the informants also pointed to a career change. The informants who identified retirement as one of the significant events in their lives were the only informants who recently experienced the said event among others, to include one who was forced to leave her work due to her osteoarthritis. As the saying goes, nobody runs forever; they were unanimous in their outlook on carrier change in the later phase of his life as a certain time that each working individual must be ready to take off in a specified period. Their responses pointed to retirement as the expected time to "stop, relax and enjoy," and a "time to exit for others to enter." However, after confronted with the real situation of retirement coupled with the unexpected events that happened along the way, each one came out the same question "what will I do now?" This situation leads to the second theme extracted in this study, Retirement: the inevitable moment and uncertainty of what lies ahead.

Mrs. L.D intended to retire at 65 . She said: "it would be just in time for my son to graduate senior high." However, Mrs. L.D's present health condition would not anymore allow any delay in her retirement, both for health and financial reasons. She expressed the intense need of the money to pay the debt incurred during her surgery, and another significant portion to pay for the housing loan, which she took earlier to finish their house. She claimed, "There is no other option; I took a lump sum, now I have to wait for five more years before I will be able to enjoy my pension." A statement expressing relief as needs were met, and at the same time dismay for the unfortunate event as it occurred prematurely as planned, suggesting unpreparedness for the supposed to be expected the event. With her present health status, this could be the reason for her statement of uncertainty, "I don't know what will happen next, I know that there is God."

Mrs. N.A was looking forward to her retirement. She stated, "I'm aware that I am growing older, and my knees are aching already, I have decided to stop working on May of 2018 so I can assist my daughter in the care of her baby." She added, "That was my final decision." What caused her to react differently was when she was informed of the her early dismissal in which she was informed in by saying, "You may not come back on January 2018, giving me my knee pain as the main reason for my dismissal," which is five months earlier because the unit manager was able to observe her 
limited mobility caused by her swollen knee. Although her limited movement was true at some point, she expressed concerns on the following; "I did the small-scale renovation of my house which will be done on March yet, and I still have some unfinished business" referring to the small group lending as stated. Her concerns suggested an interrupted life as planned, giving her all the reasons to ask, "What will I do now?"

Mrs. N.E expressed plans and excitement of the day when she would enjoy it with her family. "I will focus my attention on my family; I will give them all my time." True to her plans, when that day arrived, she spent it entirely with her family, which she considered as a need. She wasn't able to spend enough time with her family before because of her busy schedule. After retirement, she said "We renovated our house, because we have wanted to do this since then" She repeatedly claimed that "I was delighted after my retirement especially that I spent most of my time with my husband," and the said house renovation which they wanted for a long time after the earthquake in 2013. "My husband took charge of the renovation, and we were pleased then." At one glance, one may say that everything worked as planned for her most awaited event, referring to her health and financial resources, and the ability to spend her retirement as planned.

Mrs. N.E's happiness after retirement was cut short as her husband died four months after her retirement, followed by her son, another four months after the death of her husband, barely one month before this interview. She claimed, "I cannot understand, I intended to spend my life with them. My money and time are intended for them," she added while crying. "I don't know what to think anymore," a statement of despair and uncertainty. Her feeling of deep sadness was evident in her appearance, she showed signs of poor regard for grooming by the time when the interview was conducted. In her case, her retirement is supposed to be the key to her complete happiness; however, it was cut short due to the unavoidable situation.

People look forward to retirement. Likewise, it was evident among the three retired informants in this study. Plans such as; "I will retire at 65 just in time for my son to graduate senior high, I will retire on May 2018, so I can assist my daughter in the care of the baby." I will spend my time with my family." They made their plans as they looked forward to the unavoidable moments of their lives, which refers to the loss of their jobs. A study on reasons for retirement revealed that the four leading causes for retirement include; giving time for the family which was evident to one of the informants, and health issues which holds through with the two other 
respondents, and after being dismissed from the job, which is again observed to one of the informants, and after having reached the retirement age (Australian Institute of Family Studies, 1998).

Along the journey, there were emerging unexpected events that turned the situation as planed the other way around. There were events which interrupted the once refined plans for the future. Based on the data gathered, two of the three retirees needed to retire early due to health reasons, while one had reached her planned age to end her carrier as planned, but her happiness based on her objectives or her plans after retirement was cut short after the death of the loved one.

Included in the responses for retirement boiled down to being unprepared for the sudden change in situations requiring significant changes as intended. This odd feeling towards the end of their carrier happened as both informants find their retirement untimely with statements such as "I intended to retire at 65, just in time for my son to graduate senior high" and "I still have some unfinished business." People plan to work until full retirement age or force retirement at age 65; however, they failed to think that some issues may come along the way requiring them to leave earlier such as arising health conditions (Benewah, 2014).

Likewise, one intends to continue to work, but would just be found himself pushed out of a job again for health reasons (Reuters, 2014), and this is evident to one of the informants. Their unpreparedness for the supposed anticipated event which they have prepared as expected came out prematurely as planned, catching them off guard, which led to the uncertainty of the up-coming inevitable moment of their lives which is the end of their carrier. Thus, the statements "I don't know what to think," "I don't know what will happen next" and "what will I do now?" are questions of the uncertainty of what lies ahead after battling a significant situation of their lives after retirement.

The different situations pointed to the reality that an individual goes through changes in the various aspects of his life as he journeys through aging. And as one goes through it, several aspects of his life can be altered such as health and career and even other resources no matter how much preparation he does for his future. Other changes can be triggered in the form of chronic illness, which can have a direct impact on individual relationships, parenting, and career (White, 2010). These are changes that the individual is not in control of, which both modern and traditional theories of aging points out to limited life span and aging (Goldsmith, 2014). It is in this aspect that the biologic theories of aging are evident, which point to 
the degenerative process following aging, allowing some to be capable of reaching the desired time for retirement while others are not. On the other hand, due to these foreseeable events in one's life, one may consider looking at the different psychosocial theories that explain the task to be resolved accompanying the above major event. This situation is further reflected in the need to adjust to retirement and the accompanying conditions as defined by Havighurst task for late-life (Williams, 2016).

It takes a long journey before one will have the opportunity to come to this reality, the most awaited day of retirement. And such journey is bound to come across stopovers that are not even included in the itinerary but are real possibilities such as the incidents of sickness, death, and even financial instability which was claimed by the informants to hinder the plans intended for that event. So thus the question, retirement, an inevitable moment what lies ahead?

\section{Theme 3. The loss of a loved one and the accompanying pain}

Another significant life event recognized by the informants, which affected them so much was the pain caused by the death of their loved ones. While death is an unavoidable situation in the cycle of life, a reality of the mortality of man, which everyone is aware as the final destination of every human being, and normal phenomenon, the truth always remains, that pain and sorrow is inflicted to the remaining loved ones as a common denominator for their loss.

Mrs. L.D is the same single mother. She was diagnosed with cancer of the uterus, which has metastasized to her intestines. She expressed the pain of being a single mother after the death of her husband. She stated, "The death of my husband was excruciating then, it's like a part of me was taken away. Now, after several years, I have managed to move on, but the pain remains although it is not as painful as before."

Mr. N., I lost his wife from cancer of the breast, which metastasized to her bones. He took care of her for almost a year as she was bedridden. According to him, "It was very painful then, now I have slowly recovered, but I cannot help it, I still miss her so much." This is a statement coming from a husband who lost his wife three years ago. Likewise, Mrs. M.A and Mrs. N.E expressed anguish on the loss of their husbands. They can hardly say anything as both of them were bursting in tears during the separate interview conducted barely four months from the time of the death of their husbands. M.A claimed, "It's so painful, I told him why do you have to go first, why did you leave me?", "I can't 
believe that he is gone now, I feel like he is just around this house with me," she added quickly. The same concern expressed by Mrs. N.E who said, "I cannot describe the pain" as she continued crying, "I miss him so much, and I feel like I am just dreaming, why so sudden?" $A$ statement full of pain and disbelief were haunting these two recently widowed wives.

What is more painful among these two ladies was, while Mrs. NE was still grieving for the sudden loss of her husband, 4 months from the death of her husband, her son incurred a ruptured aneurysm which caused his sudden death, while he was busy preparing for the small Christmas get together party to liven up the spirit of the family in the midst of the loss of her husband on their first Christmas without him. "I cannot question God, but I cannot believe that all these are happening. Losing a husband and a son is equally painful," as claimed by Mrs. N.E. On the other hand, the researcher noticed that Mrs. N.E showed signs of not having taken care of her personal hygiene, and demonstrated sluggishness in her movements. She was the lady who lost two loved ones in a matter of four months. The same with Mrs. MYA she was lying in their living room and had not even shown signs of having taken a bath at 3 o'clock in the afternoon. Both ladies were crying the whole duration of the interview. Knowing these two ladies personally, they seemed to have succumbed to profound loneliness.

Until now, despite the length of time from the loss of their husbands, both ladies claimed the pain and sorrow caused by their loss. When asked if they were aware that they might lose their husbands, Mrs. MYA expressed awareness of the possibility of losing him "Yes because he was very ill already, but not that soon." She even added. "I don't care if I have to take care of him in his bed as long as he is alive." That was also the quick reply of Mrs. NE She said "we were just together for barely four months because of my work, and now he's gone. "Why too soon? We have not spent enough time together yet. Yes, it was an attack, but why did he die right away? I don't care if he will be dependent on me, I don't care, I will take care of him if he cannot do things by himself as long as he is alive." This same statement was also heard from Mr. MI. When asked of the awareness on the possible loss of his wife, "Yes but not that soon. I don't care if I have to take care of her in bed as long as she is with me, as long as we are together." That was the quick answer of Mr. MI.

While the two ladies complained of the intense pain four months after the death of their husbands, Mr. M.I and Mrs. L.D claimed of having forgotten slowly or recovered slowly from the pain felt several years after the incident. However, they claimed of that same feeling of intense pain 
immediately after the incident "There was so much pain before immediately after losing her," "The death of my husband was very painful then, it's like a part of me was taken away" are statements of gloom and agony caused by a lost loved one. However, both informants also stated of being able to slowly recover from its pain years after the incident. Suggesting that even if it is painful, but it heals in time. This is expected as recuperation from painful experiences happens through time, and one will not even get to notice that even the sorrow also decreases as time progresses.

While they claimed of other positive events following those years, such as the marriage of the children, the birth of grandchildren and graduation of children from college, but the death of their spouses still lingers in their minds as claimed by the informants. According to Mr. Ml., "these events even remind me of her loss. I wish that my wife is here to see all of these happening" he claimed. Edwards (2018) states that some events serve as grief triggers. She explained that these are situations that reawaken the individual's awareness of a particular loss and reminds him back of the pain. While Mr. MI. expressed giving more weight on the death of his wife in terms of significance, over the happy momentous events of his children, he clearly stated that "I am very happy for the life of my children now. But it's just that I still miss my wife especially on every happy occasion."

All three spouses were full of questions and statements of grief. They all raised concerns on pain, and feeling of disbelief and bargaining, which is a normal reaction to a loss of a loved one (Johnson, 2007). They were aware of the possible loss, but there is the common question "why too soon", "I am willing to take care of him/her even if I have to do everything for him/her" seeking answers to the reality that no matter how much effort one holds on to life, but one's life is bound to end at a specified time. As explained in the different theories of aging (Jin, 2010). The question is, who goes first? Whoever goes first leaves the loved ones in pain and anguish, which again is the common denominator for their loss which is considered a normal response to separation (Bugless, 2010). This painful reality is described in one of the specific tasks that have to be resolved among elderlies in Havighurst's Theory which included adjustment to the loss of spouse (Williams, 2016).

\section{Theme 4. The moment of change and living with life's changes}

The informants have clearly identified changes in their lives as they went through with the different significant events and hurdled with the 
disequilibrium caused by the incident. This brings to the next theme; Life and its changes. Both Mrs. M.A and Mrs. N.E claimed to be hesitant to go out yet. Mrs. N.E used to be out from their house as she was very busy with her work, while Mrs. M.A after retirement loved to go out with friends and with her daughter in-law. The typical life for these two ladies was more on going out rather than being at home. This situation changed when their husbands died as they claimed missing their husbands more when they are out. Mrs. M.A said, "I would rather stay home because I know that he is here, just watching over me. I used to be boss before because he used to do everything for me, now I do it myself, and I even talk to him while doing those things." Likewise, Mrs. N.E said, "I don't want to go out; I can feel his presence here. I would rather stay home and watch the renovation that we did before he died, and feed his roosters" "except during Sundays to attend mass," she quickly added. That was also the claim of Mrs. M.A.

Mrs. L.D and Mrs. C.H expressed concerns to have slowly turned to be dependent to their significant others, an attitude which is far from their personality before as Mrs. $\mathrm{CH}$ is a full-time housewife who does everything for the family claimed, "My mobility is quite limited now. I am slowly moving towards being dependent, I can feel it as I would still do the things that I used to do before, and my body signals me to stop." Mrs. L.D a single mother of 2 children who worked as a teacher, and who does also everything for her children claimed, "I cannot do most of the things that I used to do before, I am still weak, I just listen to my body."

Since they wanted to resume independence, their bodies would already prevent them from doing so. Mrs. L.D repeated, "I don't have any other choice but to listen to my body." While Mrs. L.D would refrain from going out in the community for reasons like, "I often stay at home because of my health condition, besides it is awkward because I have an ileostomy." Mrs. $\mathrm{CH}$. did not express concerns on limiting contacts with other people, but she claimed: "Because of my mastectomy, I don't feel good talking to people as I have that feeling that they are looking towards my chest."Both statements suggest concerns on changes in body image.

On the other hand, both mothers also claimed changes in their financial status as they faced the different regimens needed to surpass the insults caused by cancer. Mrs. $\mathrm{CH}$. claimed of giving up when she said, "I don't want my family to end up begging just for me to live," "chemotherapy was not included in my options due to financial constraint." However, recently she was convinced to be on oral anti-cancer therapy, in which 11 tablets cost 28,000 pesos. She said, "I have in me a fear of dying, but I 
cannot do anything about it, It is my decision not to go through with the different procedures."

While Mrs. L.D submitted for surgery and other procedures, in return, she has to take all the money from her retirement just for her to comply with the treatment regimen, posting financial challenges as she claimed, a significant fraction of my retirement money went to hospitalization and medication. "I have no other option, I have to wait five more years before I can enjoy my pension. I don't know what will happen next".

Mrs. LT claimed of being very forgetful as part of the physical changes caused by her age saying, "I am getting very forgetful lately, and the symptoms of my menopausal are bothersome, that I cannot do anything. I cannot do any household chores when I have my attack." These are the symptoms that she claimed that would require her to be out most of the time to divert her attention. She claimed; "My condition made me be more outgoing, I don't stay alone as I feel like I am going to lose my mind, I need to be with other people."

Mr. N.I claimed that he took care of his wife 24/7 for almost one year the death of his wife caused a total change in his daily routine. After that fateful event, he claimed, "I focused my attention on the care of my granddaughter. I took care of the child as it would somehow divert my attention from the feeling of loneliness." He also added, "I have more time now talking with the neighbors, and resuming my drinking sprees at times with my nephews as my way of entertaining myself."

Mrs. NI turned to become bold and brave to face the administration, which she used to be submissive before. She said, "I will file a complaint at DOLE, and I have talked to the general manager already regarding my condition." She is still fighting the battle regarding the due process of her retirement, which included going to the Department of Labor and Employment. She always complains of joint pain, but as usual, it is followed by the statement "This is nothing."

The different significant events encountered by the informants brought about changes in their lives. It is their way of adjusting to the various insults to live up with the demands of change to survive. As they hurdled the different significant events, varied aspects of their lives were seen to be challenged such as physical caused by illness which affected their functional capacity, psycho-emotional, as they try to balance from the loss of resources such as health, wealth, time, and even lives, and the socioexperiential aspect, as it affected their ability to interact with people. 
Among the changes mentioned by the informants were focused on health. For Mrs. L.D and Mrs. CH., the feeling of being dependent started to creep to their senses. In as much as they wanted to resume independence, their bodies would already prevent them from doing so. Statements such as, "My body signals me to stop," "I need to listen to my body" were statements of acceptance of the losing functional capacity, Fernandez (2010) states that physical limitations continued to be a common problem among cancer patients after treatment despite the high survival rate.

On the other hand, complaints of disturbing symptoms of menopausal troubled another informant as she claimed: "I cannot do any household chores when I have the attack of symptoms." This scenario reflects another manifestation of functional incapacity. The American Psychological Association presented the study showing that more women needed assistance with daily activities as they age. This pointed out to the functional capacity of the individual as one goes through the process of aging. The biologic theories of aging explain this as a normal process as one goes through physical changes approaching this stage of life (Goldsmith, 2014)

Changes were also observed to affect the psycho-emotional aspect of the informants caused by the varied significant events they encountered. They needed to come up with tough decisions to end up with the best option to lessen the effects of change caused by the significant events. The physical changes incurred by the informants had led to changes in the financial status as it cannot be denied that because of the immerging health conditions, money which is intended for other purposes was diverted to meet the present physical challenges, evident on $\mathrm{Mrs}$. $\mathrm{CH}$. who underwent surgery but claimed to refuse chemotherapy for financial reasons. She claimed of not undergoing further procedures as she thinks of the more losses that her condition would bring to the family, thus requiring more adjustment as she stated, "It is my decision, I don't want my family to end up with nothing because of me."

Mrs. L.D has to cut short of her planned retirement, a loss of time as she needed to undergo surgery and ended up spending most of her retirement money for surgery, hospitalization, and medications. She ended up using the money which is supposed to be intended for her future and other purposes, including the education of her son. After her decision, she has to wait for five more years before she can enjoy her pension, claiming no other option. The situation illustrates how one's significant event such 
as cancer can affect changes which in turn can be considered as another considerable event affecting another change in the other aspects of their lives.

Another change noted from the responses of the informants on the basis of psycho-emotional challenges was on the response Mrs. L.D Who claimed that she does not want to go out because according to her, "it is awkward to go out because I have an ileostomy." Studies showed that worse body image and lower self-esteem were observed among patients with stoma, (Kyung, Bo-Young, Eui-Jung, Soon, Kwang, Ryung, 2014). On the other hand, Mrs. $\mathrm{CH}$ did not express unwillingness to interact with other people. However, she also claimed, "Because of my mastectomy, I feel awkward talking to people as I have the feeling that they are looking towards my chest." Loss of the breast is a common manifestation on the effects of the body image that can be attributed to the loss of aesthetic features. The downfall is it may also lead to poor self-esteem (Arroyo, 2011) which can trigger another change in the life of the informant.

Psycho-emotional challenges were also noted on the responses of Mrs. N.A who claimed to have been dismissed prematurely from her job because of her osteoarthritis. She may not have lost money for hospitalization, but it led her to lose her job which again had caused an adjustment in her financial status as claimed: "I still have unfinished business." On the other hand, the significant event of losing her job awakened her real capacity to face adversities such as this. Her innate ability calls for her capability to withstand the psycho-emotional challenge in the change process as she said "I will file a complaint to DOLE," and "I have talked to the general manager regarding my case" statements showing self-efficacy despite being previously submissive. Garcia and Siddiqui (2009) states that the impact of life events depend on the overall personal traits of the individual. Thus, these traits can be utilized as she faces life's challenges.

Significant events of the informant post more challenges on the socioexperiential aspect of their personality as responses were divided between the foreseen need to continue to reach out with other people and to stay at home. The two widows who recently lose their husbands, find it more comforting to stay home as they claimed; "I would rather stay home because I know that he is here, just watching over me." She added, "I don't want to go out; I can feel his presence here." Mrs. L.A who had an ileostomy as part of her surgery, also stated that "I often stay at home because of my health condition, besides it is awkward because I 
have an ileostomy." This condition made the necessary changes as she used to be going out while she was working as a teacher.

The psychological impact of the patients with an ostomy is often on the rational aspect as it may somehow lead the individual to avoid interacting with people outside their homes (Aazam, 2010). On the other hand, the loss of job of Mrs. N.A has also led to her desire to be always at home. She said, "I am always at home to take care of my plants." These are statements coming from two working individuals whose careers just ended up because of their health condition. Mias (2017) states that work is essential to many people, and losing this would mean a noticeable loss in their identity.

On the contrary, Mr. N.I said that "I take care of my granddaughter, I need to be with other people" because he claimed the ability to divert his feeling of loneliness when he is outside. According to ASCO Cancer.Net (2015), persons who took personal care of a cancer patient may develop a routine as one's role calls for it that can turn into a total loss after the death of the patient. In return, they overcome the loss by developing new roles, which may include those that are considered as significant by the lost loved one. This is evident to Mr. N.I as he takes care of his grandchild.

Going out and being with other people was also the change claimed by Mrs. L.T who complained of the discomfort of her postmenopausal who said that, "Mycondition made me become more outgoing, I don't stayalone as I feel like I am going to lose my mind, I need to be with other people." Mrs. L.T's way of going out with other people is one way of diverting the signs and symptoms of mood swings caused by menopause. Stevenson (1983) mentioned that stress control methods are effective ways to minimize the psychological symptoms of menopausal.

Significant events affect change, and changes vary among individuals as it depends on how the individual foresees the crisis and his innate capacity to counteract to its effects. However, what is conclusive in the different situations are the changes it posts to the individual, and that one significant event affecting change can even trigger another significant event to cause another change. This brings the person to the realization of the changes in their lives.

\section{CONCLUSION}

The aging process brings about significant events that can affect changes in one's life. But life-changing events of the elderlies pointed 
out to the painful and inevitable ones. The challenge is on how to face the sense of not being in control of the situation and readjusting one's life as one continues to struggle to regain the state of balance.

The aging process ushers one to experience a decline in health coupled with vanishing resources as he struggles to regain health. Loss of resources can come in different forms such as time, and financial resources which are supposed to be spent in a preferred time but is lost in the process of maintaining health caused by old age.

Another significant life-changing event in the life of the elderlies is the inevitable moment of retirement and the uncertainty of what lies ahead. This situation reflects oness journey of the awaited time to mellow down and reap the fruits of their labor. However, the process seemed to come across different experiences that can ultimately change one's outlook of the said important event.

Getting to witness and experience the successes of the significant others are essential events in the lives of the elderlies. But the most notable is losing them and the experience of the accompanying pain in the process. This event can pose a great challenge as the elderlies address to other significant life events.

Amidst life's changes, the ability to perceive alterations is the most crucial part as one needs to adjust and readjust one's life to regain normalcy. The person can recognize the moment of change and how to live with these changes to sustain equilibrium.

\section{RECOMMENDATIONS}

The following are the recommendations based on the findings of the study:

1. For the elderly, while the aging process is one of the events in life that cannot be avoided, and as one is expected to experience changes in the different aspects of life, all measures to buffer its effects must be looked forward to along with the intention to enjoy retirement in the future.

2. Significant others can serve as support persons to assist elderlies in arriving at proper decisions and in maximizing their ability to avail of the benefits intended for them and search linkages that can help meet their needs.

3. The Department of Health and other concerned agencies which has the prerogative of coming up with programs that can address the needs of the elderlies. While there are many benefits mentioned in the 
senior citizens' act, accessibility to these services has been felt by the elderlies. Support groups for cancer, widows, and women undergoing the process of menopause as well as support for treatment of other debilitating conditions which are common to this cohort can be a great help to liven the lives of these people as they approach aging.

4. Further study is also recommended to discover other significant events and life changes common to these groups, which are not mentioned in this study.

\section{REFERENCES CITED}

Aazam D, Farida Y, Maryam R, Mansoureh Z. (2010), Quality of life in ostomy patients: a qualitative study. Retrieved from https://bit. Iy/2MJTTMX, (accessed last 8 June 2018).

Alley, D. E., Putney, N. M., Rice, M., \& Bengtson, V. L. (2010). The increasing use of theory in social gerontology: 1990-2004. Journals of Gerontology Series B: Psychological Sciences and Social Sciences, 65(5), 583-590. Retrieved from https://bit.ly/2lzTRPz, (accessed last 8 June 2018).

Arroyo, J. M. G., López M. L. D. (2011). Psychological Problems Derived from Mastectomy: A Qualitative Study, International Journal of Surgical Oncology, Volume 2011 Article ID 132461, 8 pages. Retrieved from https://bit.ly/2m3Sfhh, (accessed last 8 June 2018).

ASCO Cancer.Net. (2015).Coping with change after loss. Retrieved from https://bit.ly/2k7PsmH, (accessed last 1 May 2018).

Edwards, C. B. (2004, August 13). The psychological impact of a cancer diagnosis on families: the influence of family functioning and patients' illness characteristics on depression and anxiety. Retrieved from https://bit.ly/2kA3Zrt, (accessed last 1 May 2018).

Edwards, R. D. (2018). Grief: Loss of a Loved One. Retrieved from https:// bit.ly/2IX1gsi, (accessed last 1 May 2018). 
Garcia ,D, Siddiqui A. (2009). Adolescents effective temperaments: Life satisfaction, interpretation and memory of events, J. Posit Psychol 4:155-16

Grime, J, Richardson, J. C, Ong, Bio N. (2010). Perceptions of joint pain and feeling well in older people who reported being healthy: a qualitative study, British journal of General Practice. Retrieved from https://bit.ly/2IJq3jp, (accessed last 1 May 2018).

Jin, K. (2010). Aging and Diseases, Modern Biological Theories of Aging. Retrieved from https://bit.ly/2z5RzhC, (accessed last 1 May 2018).

Johnson, P. (2007). Coping With Death and Grief. Retrieved from https:// bit.ly/2jtr3nD, (accessed last 2 March 2018).

Kyung, S. H., Bo-Young, O, Eui-Jung, K, Soon S. C, Kwang H.K, Ryung, A. (2014). Psychological attitude to self-appraisal of stoma patients: prospective observation of stoma duration effect to self-appraisal. Retrieved from https://bit.ly/2kx4TF5, (accessed last 1 May 2018).

Laverty, S. M. (2003). Hermeneutic Phenomenology and Phenomenology: A Comparison of. Retrieved from https://bit.ly/2kns4BS, (accessed last 1 May 2018).

Lavretsky, H. (2010). Spirituality and aging disclosure aging health. Retrieved from https://bit.ly/2k3ZUeL, (accessed last 1 May 2018).

Lavretsy, H. (2014). Resilience and aging. Maryland: John Hopkins University press. https://bit.ly/1RIPGNT, (accessed last 1 May 2018).

Munhall, P. L. (2007). Nursing Research a qualitative perspective 4th ed. Toronto: Jones and Barlett Publishers.

SingHealth. (2016), Retrieved from https://bit.ly/2pWZ2bT, (accessed last 1 May 2018).

Stevenson, D. W., \& Delprato, D. J. (1983). Multiple component self control program for menopausal hot flashes. Retrieved from https:// bit.ly/2IHCJHw, (accessed last 3 June 2018). 
Wallis, C. (2014) Never too old to fight cancer. Retrieved from https://bit. ly/2IZbKHD, (accessed last 3 June 2018).

White, J R L, Farmer J M, Biesecker, B B. (2010). Exploration of transitional life events in individuals with Friedreich ataxia: Implications for genetic counselling, Behavioral Brain Function, Retrieved from https://bit.ly/2lH2isA, (accessed last 3 June 2018).

Williams, P.A.(2016). Basic Geriatric Nursing - E-Book pp29, Elsevier Inc. 6th edition. Retrieved from https://bit.ly/2knsfgw, (accessed last 3 June 2018). 